Article

\title{
Comparison of Water Curtain Effectiveness in the Elimination of Airborne Vapours of Ammonia, Acetone, and Low-Molecular Aliphatic Alcohols
}

\author{
Tomasz Węsierski * and Małgorzata Majder-Łopatka \\ Faculty of Fire Safety Engineering, The Main School of Fire Service, 52/54 Słowackiego Str., 01-629 Warsaw, \\ Poland; mmajder@wp.pl \\ * Correspondence: wesierskitomasz@poczta.onet.pl; Tel.: +48-662-007-272
}

Received: 23 August 2018; Accepted: 10 October 2018; Published: 18 October 2018

check for updates

\begin{abstract}
The paper presents results of comparative tests related to the effectiveness of water curtains in the elimination of airborne vapours of ammonia, acetone, and low-molecular aliphatic alcohols. The determined effectiveness of water curtains for acetone and methanol is by about half an order of magnitude smaller than for ammonia. An evident reduction in curtain effectiveness was recorded with an increase of the length of aliphatic chain of alcohols. Tests conducted for the four lightest representatives of primary alkanols point to an evident decrease in $t_{1 / 2}$ for further representatives according to the equation $t_{1 / 2}=203.3 \mathrm{~N}-41.5$. It was found that methanol is removed by the curtain in the shortest time from among the tested alcohols $\left(t_{1 / 2}=137 \mathrm{~s}\right)$ and 1-buthanol the most slowly $\left(t_{1 / 2}=782 \mathrm{~s}\right)$. The obtained results indicate the effectiveness of water curtains in incidents that comprise uncontrolled release of vapours of compounds being tested.
\end{abstract}

Keywords: water curtains; water curtains efficiency; rescue operations efficiency; industrial disasters; uncontrolled releases of hazardous materials; ammonia spills

\section{Introduction}

The effectiveness of water curtains in relation to clouds of hazardous substances depends on the solubility of the given substance in water, the reactivity to it or to components comprised by it, and the rate of diffusion to the droplet interior [1]. This is reflected in experimental data, as the significant effectiveness of water has been observed for the elimination of vapours of such compounds, as ammonia, hydrogen fluoride, or hydrogen chloride [1-11]. However, in the case of chlorine occurs a low water curtains efficiency [9].

An extensive study was also performed with respect to possibilities of using water curtains to eliminate hazards connected with vapours of hydrocarbons and hydrocarbon mixtures [12-15]. Given the very low solubility of hydrocarbons in water, no significant reduction in vapour concentration is observed. There is also a possibility of using curtains as barriers to limit the shifting of hydrocarbon vapour clouds, or, at appropriate intensity and direction of playing, as an element that facilitates dispersion. The dilution effect would depend among others on the intensity of jet playing, the distance between the nozzle and the point of release, and the type of nozzle [16].

A much better effectiveness of water curtains than in the case of hydrocarbon vapour was recorded for organic compounds soluble in water [11]. An additional advantage of water in events of uncontrolled release of substances mixable with water is also offered by the possibility of their becoming diluted, which allows achieving a point for which the spill ceases to pose a fire hazard.

There was no unified system for assessing the effectiveness of water curtains due to diversified research methodology and needs of end users. A different purpose is served by fire sprinklers installed 
downwards in the ceiling spaces of warehouses (internal curtains) and other ground firefighter curtains used in activities of specialized chemical rescue groups or ordinary first-order fire units [3]. In addition to these sorption properties, the firefighting curtain also creates a barrier that limits the spread of substances outside the zone. It can also be used as protection against thermal radiation, which was noticed very early [17]. Drops created from a ground firefighting curtain have twice the duration of sorbing, because they rise and then fall, which increases curtain efficiency $[3,18]$. Their modeling, as well as conducting field testing, are much more difficult because atmospheric conditions have a significant impact on their effectiveness [3,4]. Research conducted for fire curtains has shown that they can be an effective means of reducing the risk during uncontrolled releases of ammonia. A. Dandrieux et al. examined a water curtain with a capacity of $730 \mathrm{dm}^{3} / \mathrm{min}$ forming a wall with a height of $8 \mathrm{~m}$ and a width of $20 \mathrm{~m}$ placed $5 \mathrm{~m}$ from the place of release of ammonia. It has been shown that it reduces the ammonia concentration by up to $90 \%$ at a distance of $10-20 \mathrm{~m}$ from the release point of ammonia at the outflow intensity of $6.5-13.47 \mathrm{~kg} / \mathrm{min}$ [3]. Internal downwards curtains (sprinklers) in closed spaces have stable working conditions. Twomey described this type of curtain by means of the pseudo first order kinetic equation [19].

The paper presents results of tests related to the effectiveness of downwards water curtains in closed areas for substances, for which the rate of vapour reduction in air may have a measurable practical aspect. Studies were conducted of kinetics of vapour concentration reduction of ammonia, acetone, and selected low-molecular aliphatic alcohols with the use of water curtains.

\section{Experimental Part}

\subsection{Materials}

In the studies use was made of Avantor Performance Materials reagents with a purity of min. $99.5 \%$.

\subsection{Research Methodology}

In the studies, a change in concentration of vapours of tested substances was performed in the time function after subjecting their vapours to the action of overhead water curtain in the research chamber. The water jet was played with the use of a garden nozzle having a diameter of $\Phi=1 \mathrm{~mm}$. Within the studied efficiency range of curtains, the jet was characterised by droplet diameter within the range of $270 \mu \mathrm{m}<d<247 \mu \mathrm{m}$, which by definition classifies it as a fog stream $(d<1 \mathrm{~mm})$. It was assumed that the average value would be $d=260 \mu \mathrm{m}$. The characteristics of water jet droplet distribution used in our studies were presented on Figure 1A.

To study average droplet diameters the AWK Drop Spectrum Analyzer made by Zakład Elektronicznej Aparatury Pomiarowej (Electronic Measuring Equipment Plant), K $\mu \mathrm{K}$ in Warsaw (Poland) was used. The analyzer allows the determination of average diameter of droplets in the range from 0.5 to $3000 \mu \mathrm{m}$. The device scheme is shown in Figure 1B.

The obtained droplet size has both a large sorption surface and an acceptable resistance to windy weather. The water jet played from the nozzle has a similar droplet distribution parameter conforming to modern turbine extinguishing system technologies (e.g., ZIKUN Turbo-Löscher II vehicle with an average jet droplet distribution of $d=375 \mu \mathrm{m}$ ).

The tests were carried out in a tight measurement chamber having a volume of $322.4 \mathrm{dm}^{3}$ $(476 \times 676 \times 1002 \mathrm{~mm})$ as presented on Figure 2 . The fog stream came from a single nozzle provided at the centre of the upper chamber wall (7 at Figure 2). Water was flowing through the rotameter, with a precision of up to $1 \mathrm{dm}^{3} / \mathrm{h}$ (4 at Figure 2).

As regards acetone and alcohols, the research atmosphere was generated by unconstrained evaporation of samples from Petri dishes ( 8 at Figure 2) with a diameter of $9 \mathrm{~cm}$ to simulate conditions of uncontrolled release of a substance within a limited storage facility. To achieve a representative number of research trials characterised by different initial concentrations in the chamber, the evaporation times 
of samples were made to differ. In the case of ammonia, the gas was delivered from a cylinder ( 5 at Figure 2). In order to check the reproducibility of the results, at least two measurements with similar concentration values were performed.

In addition to selected substances, tests were also carried out on the dependence of the rate of absorption constants on the intensity of spraying $\left(25 \mathrm{dm}^{3} \mathrm{~h}^{-1} \leq q \leq 95 \mathrm{dm}^{3} \mathrm{~h}^{-1}\right)$. The water temperature used in the tests was in the range $283 \mathrm{~K} \leq T \leq 295 \mathrm{~K}$. Concentrations of acetone, ethanol, 1-propanol, and 1-butanol were measured with the use of an MSA Sirius multisensory appliance with the use of a photoionisation detector (2 at Figure 2). On the other hand, for methanol (mainly due to excessively high ionisation potential), use was made of a sensor of catalytic combustion. The indicated computational values were in each case multiplied by the appropriate calibration coefficient.
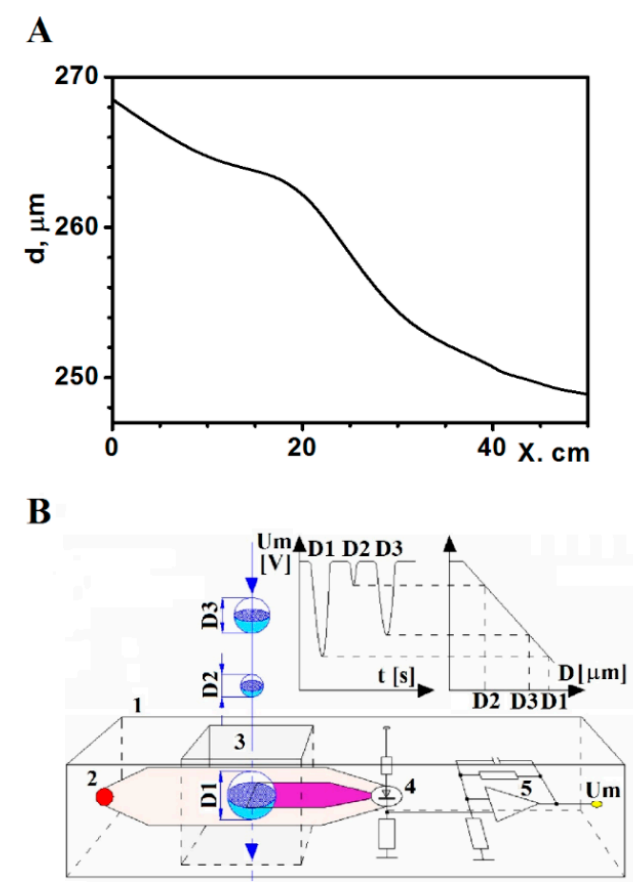

Figure 1. (A) Characteristics of droplet distribution of water stream used in tests. Nozzle with a diameter of $\Phi=1 \mathrm{~mm}$; $\mathrm{d}$-average droplet diameter; $X$-distance from the curtain centreline. (B) AWK Drops Spectrum Analyzer scheme: 1-probe, 2-transmitter, 3-measuring space, 4-receiver, 5-electronical arrangement, D1, D2, and D3-adequate size of droplets.

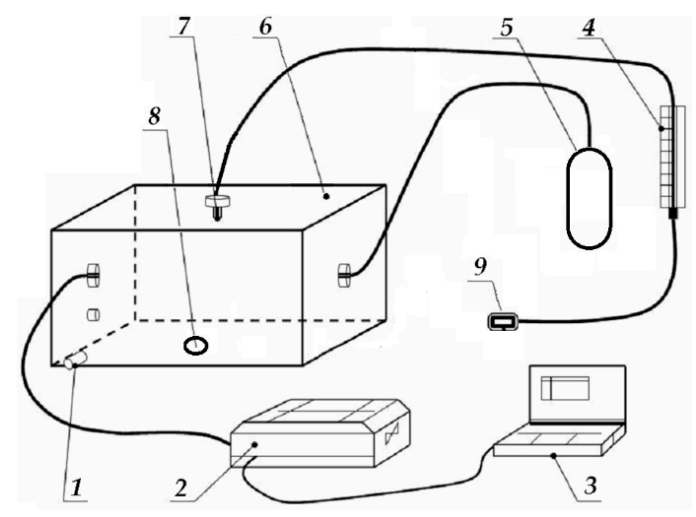

Figure 2. Diagram of the research stand: (1) draining valve, (2) gas analyser, (3) recorder, (4) rotameter, (5) ammonia cylinder (in case of ammonia), (6) measurement chamber, (7) spray nozzle, (8) Petri dish (for acetone and alcohols), (9) water supply. 


\section{Results and Discussion}

The changes in concentration of tested vapours in all the tested cases were characterised by expotential fading in kinetic range. The authors of the article postulate that the course of the process may be described with the use of a differential equation similar to reaction of the pseudo first order in which the apparent constant absorption rate $k_{p}$ comprises the effectiveness of the water curtain, droplet distribution of droplets forming the absorption surface $S_{w}$ within a time unit, coefficient of jet geometry, and time of droplet falling through the gas cloud according to Equation (1):

$$
-\frac{d[A]}{d t}=-k_{p}[A]=-k_{G} S_{w} t_{f}[A]=-k G t_{f} S_{w}[A]
$$

in which

[A]: concentration of vapours of the tested substance in the chamber [ppm]

G: coefficient of jet geometry understood as a volume covered by the jet of the curtain in relation to the volume of the measurement chamber

$k$ : actual constant of the rate of absorption process $\left[\mathrm{m}^{-2} \mathrm{~s}^{-1}\right]$

$k_{p}$ : apparent constant of the rate of absorption process $\left[\mathrm{s}^{-1}\right]$

$k_{G}$ : geometric constant of the rate of absorption process $\left[\mathrm{m}^{-2} \mathrm{~s}^{-1}\right]$

$S_{w}$ : absorption surface generated in a time unit $\left[\mathrm{m}^{2} \mathrm{~s}^{-1}\right]$

$t_{f}$ : time of droplet passage through gas cloud [s]

A similar expotential nature of curves depicting concentration dependencies in the function of time has already been recorded beforehand for ammonia [19]. Such an assumption appears to be justified and results from the conditions of the experiment. Continuous administration of water in significant excess to sorbed substances causes its concentration to be considered constant. Furthermore, the rate of the absorption process could depend on such elements as speed of substance diffusion to the surface of the falling droplet, process of substance bonding on the droplet surface, local changes of pressure connected with splaying the liquid jet from the curtain that hasten the diffusion rate, permeation of the substance inside the droplet, time of droplet dropping from the curtain to the ground surface, and geometry of jet from the nozzle in relation to the geometry of the measurement chamber.

Since gas is intensively mixed by the stream of the water curtain, the process speed will not be controlled by diffusion but instead by the sorption rate. In this case, a linear dependence of the sorption rate vs. time can be expected. Therefore, the amount of absorbed substance on the droplet surface should be directly proportional to the flight time of the drop in a cloud of sorbed gas. The same relationship occurs, for example, for electrochemical processes in which the rate of processes controlled by adsorption is directly proportional to the rate of change of potential [20,21]. For diffusion-controlled processes, mixing solutions with inert gas increases the diffusion rate. Under these conditions, the process rate is controlled by other steps (e.g., adsorption or chemical reaction) [20].

After a longer time of curtain operation, the absorption rate of vapours also depends on the dynamic balance state between liquid vapours and the solution formed from the curtain (if the solution is not drained from the chamber, what is equivalent to a situation of faulty work of a sewer on warehouse area).

The effectiveness of the water curtain in a time unit $(q)$ is in proportion to the number of droplets $(n)$ administered in a time unit and the average volume of a single droplet $\left(V_{k}\right)$ according to Equation (2):

$$
q=\frac{n \cdot V_{k}}{t}=\frac{4 n \pi R^{3}}{3 t}
$$

in which

$q$ : effectiveness of the water curtain in time unit $\left[\mathrm{m}^{3} / \mathrm{s}\right]$ 
$V_{k}:$ average volume of single droplet $\left[\mathrm{m}^{3}\right]$

$R: \quad$ average radius of single droplet $[\mathrm{m}]$

The sorption surface generated in a time unit by the stream of falling droplets $S_{w}$ may be related to the water effectiveness of the curtain $q$, time of half-life concentration reduction $\mathbf{t}_{1 / 2}$, and geometric constant of process rate $k_{G}$, which is presented in Equations (3) and (4).

$$
\begin{gathered}
S_{w}=\frac{4 n \pi R^{2}}{t}=\frac{4 n \pi R^{3}}{R t}=\frac{4 n \pi\left(\frac{3 t q}{4 \pi \cdot n}\right)}{R t}=\frac{3 q}{R} \\
t_{1 / 2}=\frac{\ln 2}{k_{p}}=\frac{\ln 2}{k_{G} \cdot S_{w} \cdot t_{f}}=\frac{R \ln 2}{3 k_{G} \cdot t_{f} \cdot q}
\end{gathered}
$$

in which

$k_{1 / 2}$ : time of half-life concentration reduction [s].

Taking the above equations into account, a linear dependence may be observed between the time of half-life reduction of concentration $t_{1 / 2}$ and the inverse of water efficiency of the curtain in a time unit $q$.

For practical reasons, the efficiency of water curtain $q$ in paper will be given in $\left[\mathrm{dm}^{3} / \mathrm{h}\right]$.

\subsection{Ammonia}

A change in $\mathrm{NH}_{3}$ concentration taking place in the chamber is in all the analysed cases of a nature similar to the expotential disappearance, which points to the fact that the rate of the process is directly proportional to ammonia concentration. The course of the process in the kinetic aspect may be consequently described in accordance with the kinetic reaction of pseudo first order, which confirms the correctness of assumptions defined by Formula (1). Examples of curves depicting the dependence of ammonia concentration in the function of time of administration of water jets were presented in Figure 3.

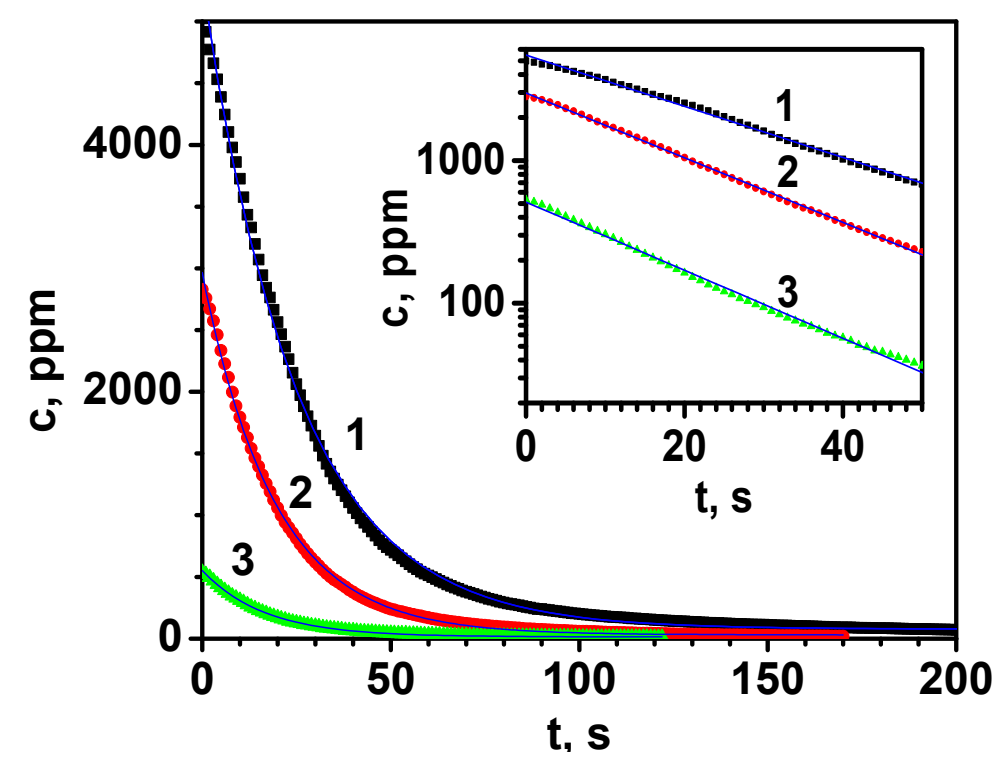

Figure 3. Time dependence curves of ammonia concentration during provision of water curtain. Nozzle diameter $\Phi=1 \mathrm{~mm}$. Initial concentration of ammonia (1) $4950 \mathrm{ppm}$, (2) $2860 \mathrm{ppm}$, and (3) 550 ppm. Insert: $\ln (c)=\mathrm{f}(t)$ in kinetic range. Water flow efficiency $q=95 \mathrm{dm}^{3} \mathrm{~h}^{-1}$.

The maximum value of apparent constant absorption rates $k_{p}$ of ammonia vapours determined in the kinetic process was presented in Table 1. 
Pursuant to Formula (4), it has been ascertained that the effectiveness of the curtain constitutes a function of water flow efficiency $q$ (Figure 4). This is suggested by the fact of a linear dependence between the time of half-life fading of ammonia concentration $\mathbf{t}_{1 / 2}$ and the inverse of water flow efficiency $q$ of the curtain $q$ (insert Figure 4). This dependence may be described by the equation $t_{1 / 2}=1094 q^{-1}$ with correlation of $R^{2}=0.996$.

No significant effect of water temperature on the kinetics in the range $283 \mathrm{~K} \leq T \leq 295 \mathrm{~K}$ was observed.

Table 1. Values of apparent constant rates of the absorption process $k_{p}$ and times of half-time reduction of ammonia concentration $t_{1 / 2} \cdot c_{0}$-initial concentration of ammonia in chamber.

\begin{tabular}{cccc}
\hline$c_{\mathbf{o}}$ & $\boldsymbol{q}$ & $\boldsymbol{k}_{\boldsymbol{p}}$ & $\boldsymbol{t}_{\mathbf{1 / 2}}$ \\
\hline $\mathbf{P p m}$ & $\mathbf{d m}^{\mathbf{3}} \mathbf{h}^{\mathbf{- 1}}$ & $\mathbf{s}^{-\mathbf{1}}$ & $\mathbf{S}$ \\
\hline 4950 & 95 & 0.0413 & 16.78 \\
2860 & 95 & 0.0521 & 13.29 \\
550 & 95 & 0.0549 & 12.62 \\
147 & 72 & 0.0467 & 14.84 \\
156 & 62 & 0.0383 & 18.11 \\
144 & 45 & 0.0290 & 23.88 \\
152 & 35 & 0.0220 & 31.51 \\
\hline
\end{tabular}

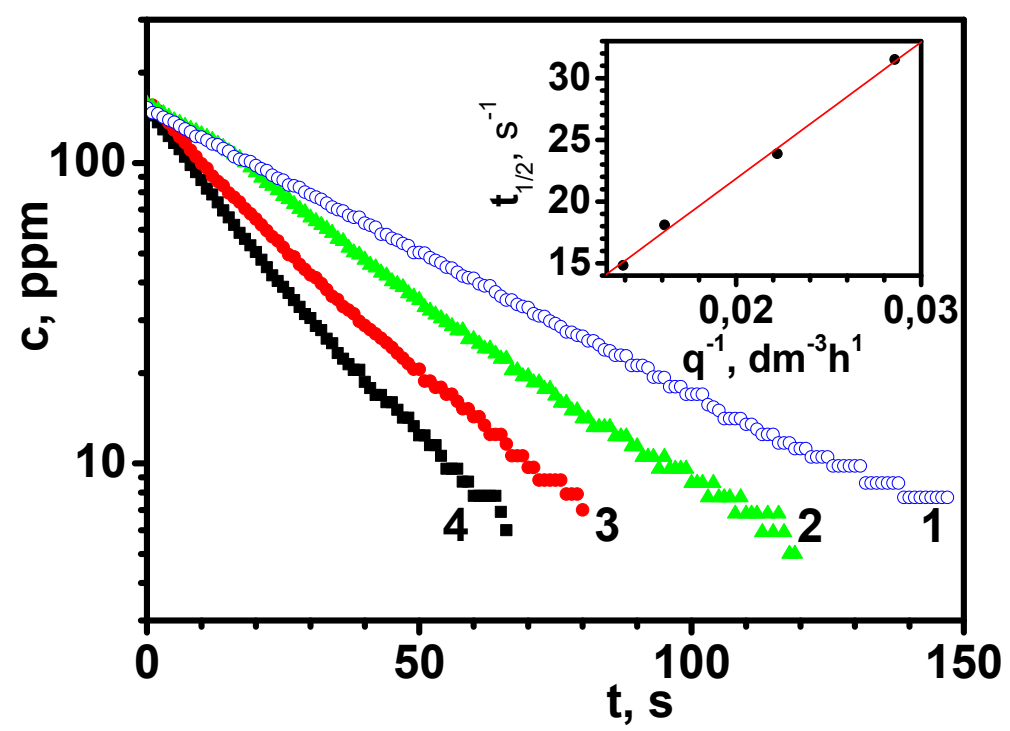

Figure 4. Dependence curves of the ammonia concentration logarithm in the time function for water flow efficiency of the curtain equalling to: (1) $q=35 \mathrm{dm}^{3} \mathrm{~h}^{-1}$, (2) $q=45 \mathrm{dm}^{3} \mathrm{~h}^{-1}$, (3) $q=62 \mathrm{dm}^{3} \mathrm{~h}^{-1}$, and (4) $q=72 \mathrm{dm}^{3} \mathrm{~h}^{-1}$. Insert: curve of dependence of the time of half-life reduction of ammonia concentration in the function of water flow efficiency of the curtain.

\subsection{Alcohols}

Changes in concentration of alcohol vapours in all the tested cases had the nature of an expotential fading (Figure 5). 

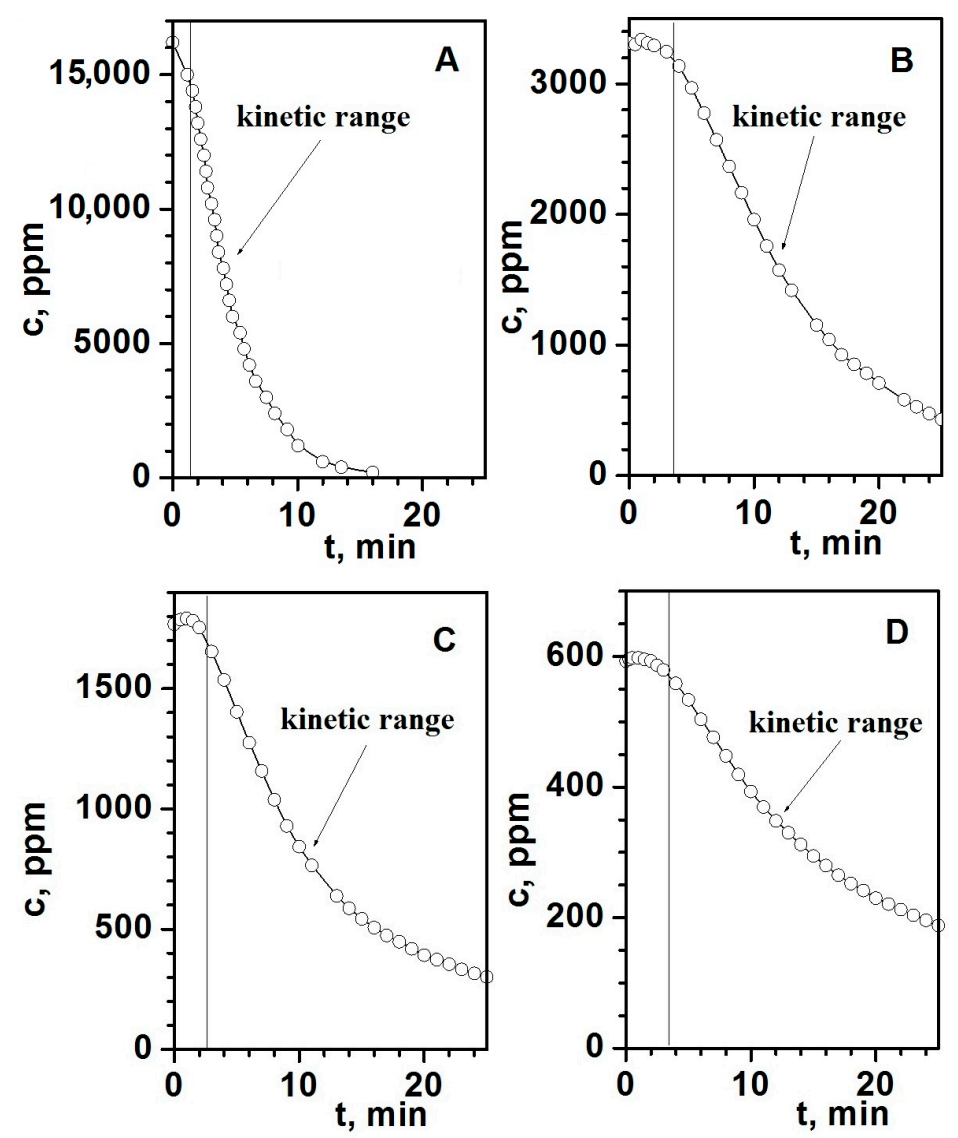

Figure 5. Concentration time dependent curves in time of water curtain work for vapours (A) methanol, (B) ethanol, (C) 1-propanol, and (D) 1-butanol. Water flow efficiency $q=35 \mathrm{dm}^{3} \mathrm{~h}^{-1}$.

A similar expotential nature of concentration dependence curves in the function of time was recorded for ammonia. Regarding primary alcohols in the initial part of the course, a period of constant level of vapour concentration has been recorded (minute 1-3). This is due to the time needed for lifting and mixing of alcohol vapours that are heavier than air. It is a period in which a reduction in alcohol vapour concentration through the curtain is compensated for by enforced diffusion of such vapour towards upper parts of the chamber. After equalisation of vapour concentration in the whole system, there is a reduction of concentration as a result of sorption-based action of water.

It is clear that the rate of absorption of vapours of studied alcohols tends to decrease with the increase in the length of the hydrocarbon chain (Table 2, Figure 6).

Table 2. Kinetic parameters of water curtain for different water efficiencies of investigated alcohols: $k_{p}$-apparent sorption rate constant, $t_{1 / 2}$-half-life decay value (kinetic range).

\begin{tabular}{cccc}
\hline & $\boldsymbol{q}$ & $k_{p}$ & $t_{\mathbf{1 / 2}}$ \\
\cline { 2 - 4 } & $\mathbf{d m}^{\mathbf{3}} \mathbf{h}^{-\mathbf{1}}$ & $\mathbf{s}^{-\mathbf{1}}$ & $\mathbf{s}$ \\
\hline Methanol & 35 & 0.00506 & 137 \\
Ethanol & 35 & 0.00163 & 425 \\
1-propanol & 35 & 0.00132 & 523 \\
1-buthanol & 35 & 0.00089 & 782 \\
\hline
\end{tabular}




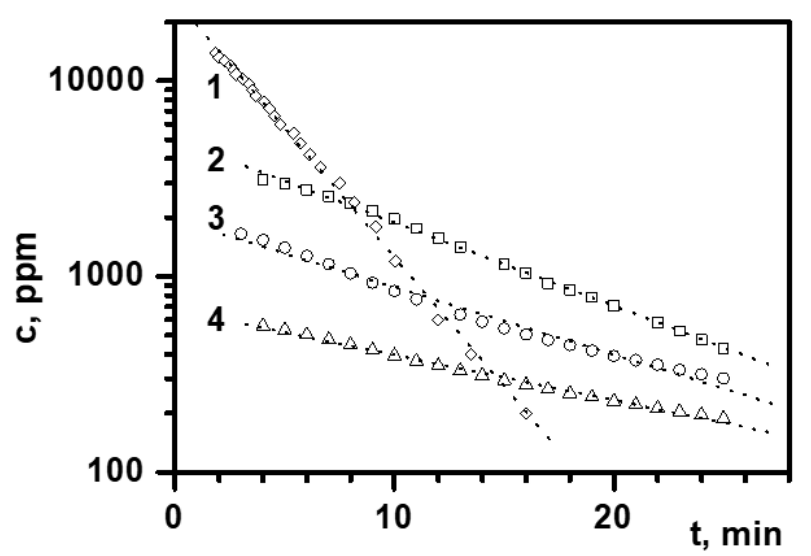

Figure 6. Kinetic curves of sorption by water curtain for vapours of (1) methanol, (2) ethanol, (3) 1-propanol, and (4) 1-butanol. Water flow efficiency $q=35 \mathrm{dm}^{3} \mathrm{~h}^{-1}$.

This is manifested by linear growth of the time of half-life reduction in alcohol vapour concentration in the function of the number of coal atoms in the aliphatic chain (Figure 7). The correlation coefficient $R^{2}$ for this matching amounts to 0.97 . This dependence is described by the equation $t_{1 / 2}=203.3 \mathrm{~N}-41.5$.

No significant effect of water temperature on the kinetics in the range $283 \mathrm{~K} \leq T \leq 295 \mathrm{~K}$ was observed.

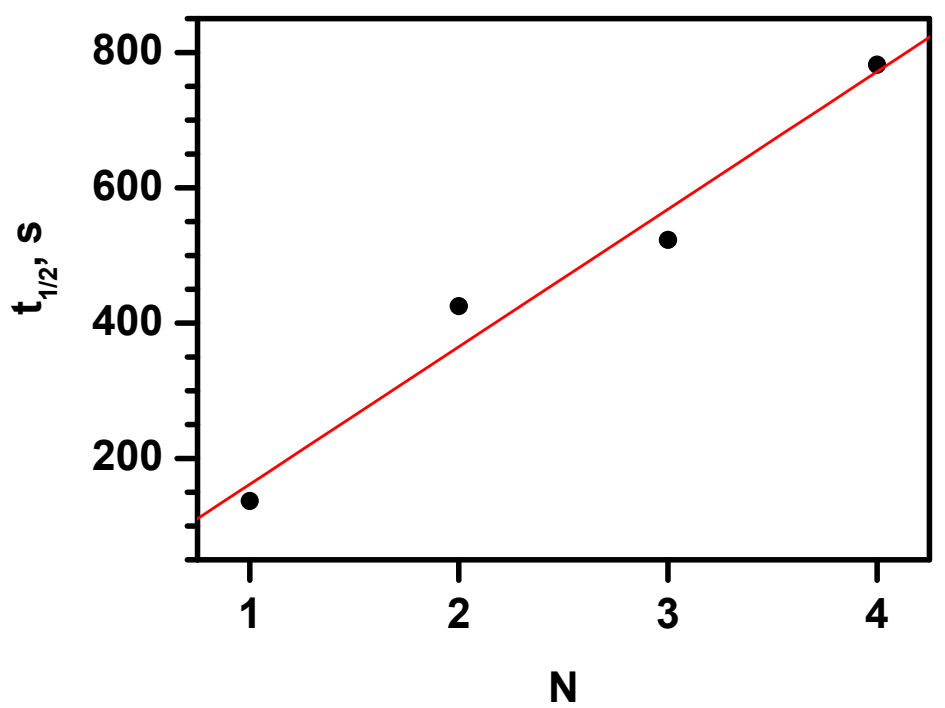

Figure 7. Dependence of half-life concentration reduction time $t_{1 / 2}$ on the number of coal atoms in the aliphatic chain of tested alcohols. Water flow efficiency $q=35 \mathrm{dm}^{3} \mathrm{~h}^{-1}$.

\subsection{Acetone}

Examples of dependence curves of acetone vapour concentration at a constant water flow efficiency $\left(q=25 \mathrm{dm}^{3} \mathrm{~h}^{-1}\right)$ were presented on Figure 8. Similarly to the case of primary alcohols, in the initial stage of water jet administration, a period of a constant level of acetone vapour concentration was recorded. Yet, this period was relatively short and regardless of vapour concentration did not last longer than one minute. Similarly to primary alcohols and ammonia, a change in acetone concentration in the research chamber in all the analysed cases was found to be of a nature similar to expotential fading. This confirms the legitimacy of approximation of the reduction process of acetone vapour concentration in the function of time by Equation (1), which is similar to the equation of reaction of pseudo first order. In order to assess the maximum reduction rate of acetone vapour concentration 
in the chamber, an analytical range was adopted between the first and the fifth minute, as has been presented as a logarithm of concentration in the function of time on Figure 9.

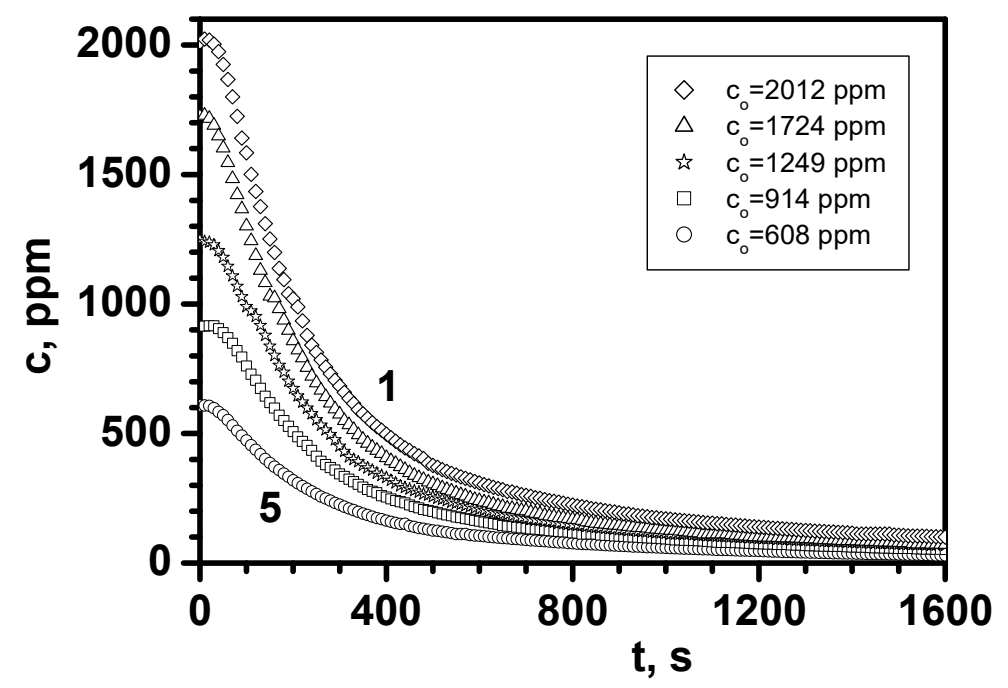

Figure 8. Curves of dependence of acetone concentration in time function during administration of water jets from a water curtain with a nozzle diameter of $\Phi=1 \mathrm{~mm}$. Initial concentration of acetone (1) 2012 ppm, (2) 1724 ppm, (3) 1249 ppm, (4) 914 ppm, and (5) 608 ppm. Water flow efficiency $q=25 \mathrm{dm}^{3} \mathrm{~h}^{-1}$.

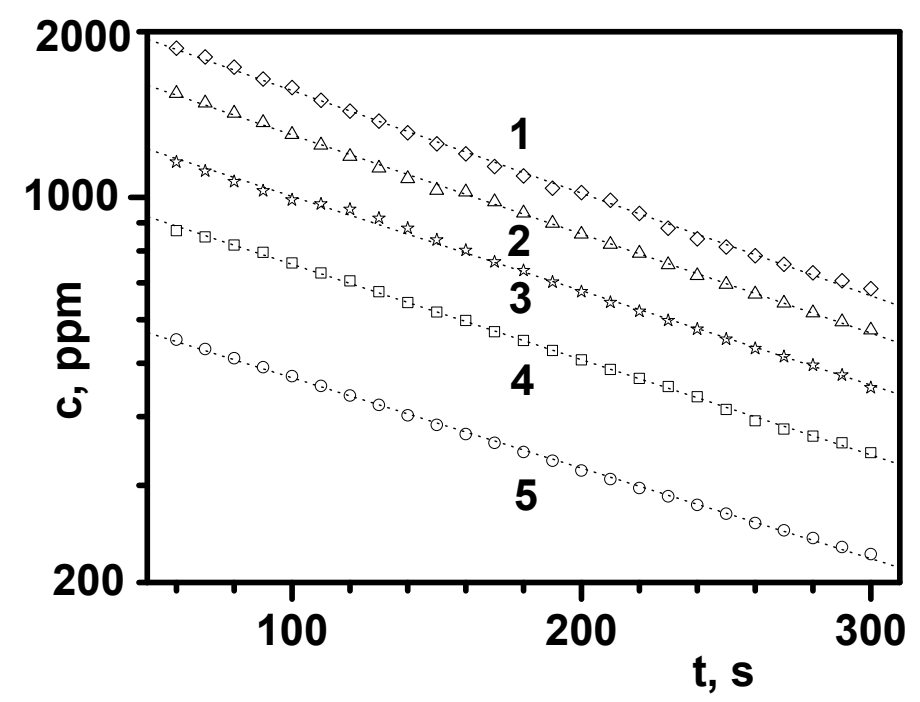

Figure 9. Dependence curves of acetone concentration logarithm in the function of time. The analysed kinetic range between $60 \mathrm{~s} \leq t \leq 300 \mathrm{~s}$. Initial acetone concentration in the chamber (1) $2012 \mathrm{ppm}$, (2) $1724 \mathrm{ppm}$, (3) $1249 \mathrm{ppm}$, (4) $914 \mathrm{ppm}$, and (5) $608 \mathrm{ppm}$. Water flow efficiency $q=25 \mathrm{dm}^{3} \mathrm{~h}^{-1}$.

The average value of $k_{p}$ with accuracy up to one standard deviation amounts to $k_{p}=(4.04+/-0.17)$ $\times 10^{-3} \mathrm{~s}^{-1}$ (Table 1 ). The variability coefficient equals to $4.2 \%$ and implies an insignificant dispersion of recorded values of apparent constant absorption rate $k_{p}$.

Studies of the impact exerted by effectiveness of water curtain on the absorption rate of acetone vapour were carried out for q equalling to $25,35,43$, and $57 \mathrm{dm}^{3} / \mathrm{h}$. According to expectations, an increase was recorded of the apparent value of constant absorption rate $k_{p}$ and the linear dependence of half-life reduction time of acetone concentration $t_{1 / 2}$ in the function of inverse of water efficiency of the curtain (Figures 10 and 11, Table 3). The latter dependence may be described in the scope studied by equation $t_{1 / 2}=2274 q^{-1}+85.3$ with correlation equalling to $R^{2}=0.977$. 


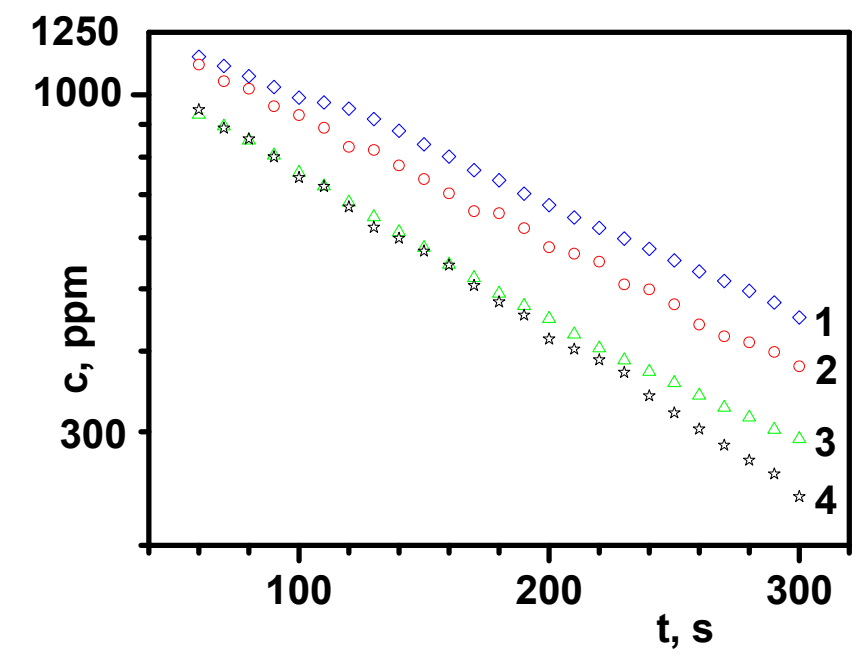

Figure 10. Curves of dependency of the acetone concentration logarithm in time function for effectiveness of water curtain (1) $q=25 \mathrm{dm}^{3} \mathrm{~h}^{-1}$, (2) $q=35 \mathrm{dm}^{3} \mathrm{~h}^{-1}$, (3) $q=43 \mathrm{dm}^{3} \mathrm{~h}^{-1}$, and (4) $q=57 \mathrm{dm}^{3} \mathrm{~h}^{-1}$. Analysed kinetic scope ranges between $60 \mathrm{~s} \leq t \leq 300 \mathrm{~s}$.

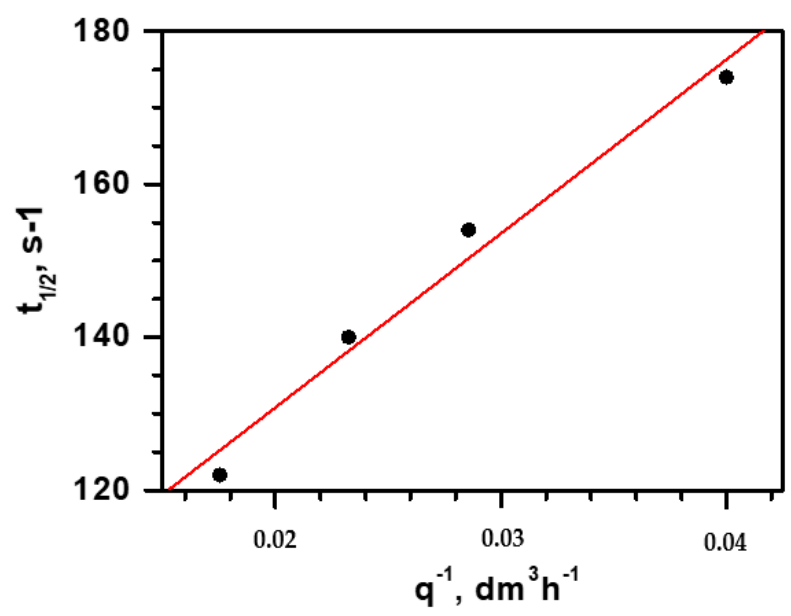

Figure 11. Dependence curve of the time of half-life acetone concentration reduction in the function of inverse water curtain efficiency.

Table 3. Kinetic parameters of the acetone absorption rate for various water efficiency levels of the curtain: $k_{p}$-apparent constant of the absorption rate, $t_{1 / 2}$-time of half-life concentration reduction (kinetic rang).

\begin{tabular}{ccc}
\hline $\boldsymbol{q}, \mathbf{d m}^{\mathbf{3}} \mathrm{h}^{-\mathbf{1}}$ & $\boldsymbol{k}_{\boldsymbol{p}} \mathbf{s}^{-\mathbf{1}}$ & $\boldsymbol{t}_{\mathbf{1 / 2}}, \mathbf{s}$ \\
\hline 25 & 0.00399 & 174 \\
35 & 0.00450 & 154 \\
43 & 0.00495 & 140 \\
57 & 0.00570 & 122 \\
\hline
\end{tabular}

No significant effect of water temperature on the kinetics in the range $283 \mathrm{~K} \leq \mathrm{T} \leq 295 \mathrm{~K}$ was observed.

\section{Conclusions}

The results of the concluded tests have clearly proven the legitimacy of applying water curtains to reduce the concentration of airborne vapours of tested compounds. The effectiveness of water curtains was found to be decidedly the highest for ammonia. This was confirmed by the time of half-life reduction of $\mathrm{NH}_{3}$ concentration for the comparative water output of $q=35 \mathrm{dm}^{3} \mathrm{~h}^{-1}$ amounting to 
$t_{1 / 2}=31.5 \mathrm{~s}$. In comparison, for acetone or methanol this value equals 137 and $154 \mathrm{~s}$, respectively. An obvious reduction was recorded of the effectiveness of curtains with the growth of the length of the aliphatic chain of alcohols. Tests performed for the four lightest representatives of primary alkanols point to a clear decrease of $t_{1 / 2}$ for further representatives in accordance with the equation $t_{1 / 2}=203.3 N-41.5$. Hence, it seems that from among the tested alcohol, methanol appears to be eliminated by curtains in the most effective way $\left(t_{1 / 2}=137 \mathrm{~s}\right)$, while 1-butanol in the slowest way $\left(t_{1 / 2}=782 \mathrm{~s}\right)$. The effectiveness of acetone elimination is similar to the effectiveness of curtains for methanol and hence much higher than for ethanol, propan-1-ol, or butan-1-ol.

The obtained values of kinetic parameters are high not to deny the legitimacy of the use of curtains for uncontrolled releases of tested substances but also with view to certain additional effects, such as dilution and the reduction of the evaporation of their spills or the elimination of a hazard by electrostatic charges.

Author Contributions: All authors conceived the idea of experiment, conducted the experimental part interpreted and discussed the experimental results. M.M.-Ł.; translated the article, provided manuscript formatting. T.W; writing-original draft preparation.

Funding: The research was carried out as part of the DOB-BIO6/06/11/2014 project "Mobile turbine rescue and firefighting system" financed by The National Centre for Research and Development in Poland (NCBiR).

Conflicts of Interest: The authors declare no conflicts interests.

\section{References}

1. Shen, X.; Zhang, J.; Hua, M.; Pan, X. Experimental research on decontamination effect of water curtain containing compound organic acids on the leakage of ammonia. Proc. Safety Environ. Prot. 2017, 105, $250-261$. [CrossRef]

2. Hua, M.; Shen, X.; Zhang, J.; Pan, X. Protective water curtain ammonia absorption efficency enhancement by inorganic acid and surfactants additives. Proc. Saf. Environ. Prot. 2018, 116, 737-744. [CrossRef]

3. Dandrieux, A.; Dusserre, G.; Ollivier, J.; Fournet, H. Effectiveness of water curtains to protect firemen in case of an accidental release of ammonia: Comparison of the effectiveness for two different release rates of ammonia. J. Loss Prev. Ind. 2001, 14, 349-355. [CrossRef]

4. Isnard, O.; Soulhac, L.; Dusserre, G. Numerical simulation of ammonia dispersion around a water curtain. J. Loss Prev. Ind. 1999, 12, 471-477. [CrossRef]

5. Hua, M.; Qi, M.; Yue, T.; Pi, X.; Pan, X.; Jiang, J.C. Experimental research on water curtain scavenging ammonia dispersion in confined space. Procedia Eng. 2018, 211, 256-261. [CrossRef]

6. Cheng, C.; Tan, W.; Du, H.; Liu, L. A modified steady-state model for evaluation of ammonia concentrations behind a water curtain. J. Loss Prev. Ind. 2015, 36, 120-124. [CrossRef]

7. Węsierski, T.; Majder-Łopatka, M.; Matuszkiewicz, R.; Porowski, R. Study on the effectiveness of water curtains to control of ammonia vapors during its uncontrolled release. Przem. Chem. 2012, 91, 1424-1426. (In Polish)

8. Bara, A.; Dusserre, G. The use of water curtains to protect firemen in case of heavy gas dispersion. J. Loss Prev. Ind. 1997, 10, 179-183. [CrossRef]

9. Dandrieux, A.; Dusserre, G.; Ollivier, J. Small scale field experiments of chlorine dispersion. J. Loss Prev. Ind. 2002, 15, 5-10. [CrossRef]

10. Fthenakis, V.M.; Blewitt, D.N. Mitigation of hydrofluoric acid release: Simulation of the performance of water spraying systems. J. Loss Prev. Ind. 1993, 6, 209-218. [CrossRef]

11. Węsierski, T. Effectiveness of water curtains during fighting against vapors of saturated linear low molecular mass alcohols during its uncontrolled release. Przem. Chem. 2015, 94, 728-730. (In Polish)

12. Rana, M.A.; Mannan, M.S. Forced dispersion of LNG vapor with water curtain. J. Loss Prev. Ind. 2010, 23, 768-772. [CrossRef]

13. Rana, M.A.; Cormier, B.R.; Suardin, J.A.; Zhang, Y.; Mannan, M.S. Experimental study of effective water spray curtain application in dispersing liquefied natural gas vapor clouds. Proc. Saf. Prog. 2008, 27, 345-353. [CrossRef] 
14. Rana, M.A.; Mannan, M.S. Water Curtain Application for Forced Dispersion of LNG Vapor. In Proceedings of the O'Connor 9th Topical Conference on Natural Gas Utilization, AIChE Spring National Meeting, Tampa, FL, USA, 26-30 April 2009.

15. Rana, M.A.; Guo, Y.; Mannan, M.S. Use of water spray curtain to disperse LNG vapor clouds. J. Loss Prev. Ind. 2010, 23, 77-88. [CrossRef]

16. Qi, M.; Yue, T.; Hua, M.; Pan, X.; Jiang, J. Experimental research on water curtain diluting heavy gas dispersion in limited space with no ventilation. J. Loss Prev. Ind. 2016, 43, 471-478. [CrossRef]

17. Thomas, P.H. Absorption and Scattering of Radiation by Water Sprays of Large Drops. Br. J. Appl. Phys. 1952, 3, 385-393. [CrossRef]

18. Fthenakis, V.M.; Schatz, K.W.; Rohatgi, U.S.; Zakkay, V. Computation of Flow Fields Induced by Water Spraying of an Unconfined Gaseous Plume. J. Fluids Eng. 1993, 115, 742-750. [CrossRef]

19. Twomey, S. Atmospheric Aerosols; Elsevier Scientific Publishing Company: Amsterdam, The Netherlands, 1977.

20. Galus, Z. Fundamentals of Electrochemical Analysis; Horwood: Warsaw, Poland, 1994.

21. Laviron, E. Influence de l'adsorption du dépolarisant ou d'un produit de la réaction électrochimique sur les réaction électrochimique sur les courants polarographiques. Bull. Soc. Chim. Fr. 1968, 5, 2256-2260.

(C) 2018 by the authors. Licensee MDPI, Basel, Switzerland. This article is an open access article distributed under the terms and conditions of the Creative Commons Attribution (CC BY) license (http:/ / creativecommons.org/licenses/by/4.0/). 